\title{
Disseminated superficial actinic porokeratosis
}

\section{Mrinal Gupta}

\author{
Sudhaa Skin Centre, 35-A, Lane No-7, Tawi Vihar, Sidhra, Jammu, J\&K, India
}

Corresponding author: Dr. Mrinal Gupta, E-mail: drmrinalgupta@yahoo.com

Sir,

The porokeratoses, first described by Mibelli and Respighi in 1893, are a group of disorders of abnormal epidermal keratinization characterized by keratotic lesions with an atrophic center and a prominent peripheral ridge, with a typical histological hallmark, the cornoid lamella. Classically, five clinical variants are recognized: classic porokeratosis of Mibelli, disseminated superficial actinic porokeratosis (DSAP), disseminated superficial porokeratosis, porokeratosis palmaris et plantaris disseminata, and linear porokeratosis. Apart from these five clinical variants, a number of atypical forms such as facial porokeratosis, giant porokeratosis, punched-out porokeratosis, hypertrophic verrucous porokeratosis and reticulate porokeratosis also have been reported in literature [1]. We report a case of DSAP over the face of a 40-year old female.

A 40-year old female presented to us with a history of gradually progressive, asymptomatic eruption over her face for the last six years. The patient was otherwise well, with no systemic complaints. She denied any history of skin cancer, radiation, or heavy sun exposure or any changes in the lesions with sun exposure, but gave history of similar lesions in her sister.

Cutaneous examination revealed multiple, superficial, annular, hyperpigmented, atrophic plaques, 1 to $5 \mathrm{~mm}$ in diameter with a slightly raised peripheral border over the cheeks (Fig. 1). A skin biopsy of the lesions was performed which revealed the presence of well-formed cornoid lamellae with dyskeratotic cells at their base, confirming the diagnosis of porokeratosis (Fig. 2).

The patient was started on once daily application of tretinoin $0.1 \%$ gel along with sunscreens, and after eight weeks of therapy, there was mild improvement in the symptoms.

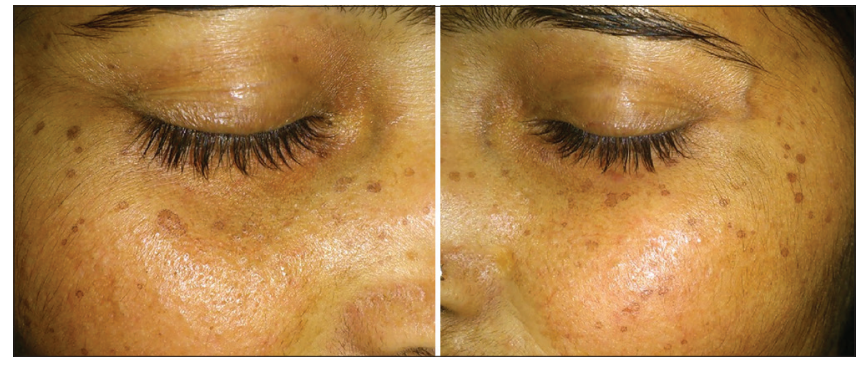

Figure 1: Annular hyperpigmented atrophic plaques with slightly raised peripheral border over the face.

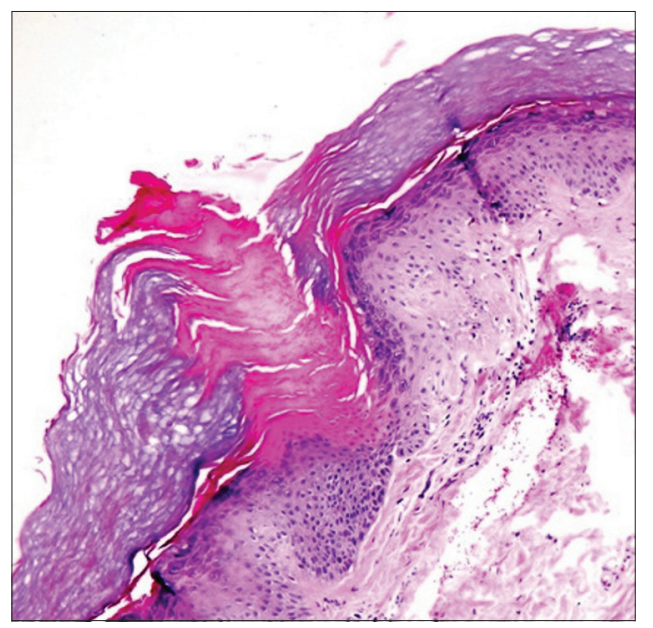

Figure 2: Histopathology showing a characteristic cornoid lamella (H\&E 40X).

DSAP is the most common variant of porokeratosis. Its onset is usually in the third or fourth decade of life and involves the sun-exposed skin, but paradoxically, the face is involved in only $15 \%$ of cases [2]. DSAP is inherited as an autosomal dominant condition, with reduced penetrance at younger ages. Several mutations have been identified in the SSHl gene on chromosome 12, which encodes a phosphatase that plays a vital role in actin dynamics. Although the specific etiology is unknown, porokeratosis are thought to originate from clonal proliferation of

\footnotetext{
How to cite this article: Gupta M. Disseminated superficial actinic porokeratosis. Our Dermatol Online. 2017;8(2):241-242 
abnormal keratinocytes and the risk factors include family history, light colored skin, ultraviolet or ionizing radiation exposure, internal malignancies, and immunosuppression [3]. Lesions are typically asymptomatic but some patients may experience pain, pruritus, or cosmetic concerns. Clinically, the characteristic lesion is a crateriform horny papule that gradually extends to form a circinate plaque with a distinct ridge like border and atrophic center, which is histopathologically characterized by cornoid lamella [2].

Several treatment modalities have been described which include keratolytic agents, topical 5-flourouracil, topical and oral retinoids, topical imiquimod, cryotherapy, photodynamic therapy, carbon dioxide laser ablation, dermabrasion, diclofenac sodium 3\% gel and excision [4]. Education regarding sun protection and regular checks for malignant conditions is needed in patients with DSAP as all of the clinical variants of porokeratosis have the potential for malignant transformation with an overall incidence of $7.5 \%$ to $11 \%[3,5]$.

\section{REFERENCES}

1. Sertznig P, von Felbert V, Megahed M. Porokeratosis: present concepts. J Eur Acad Dermatol Venereol. 2012;26:404-12.

2. Shumack SP, Commens CA. Disseminated superficial actinic porokeratosis: A clinical study. J Am Acad Dermatol. 1989;20:1015-22.

3. sXia JH, Yang YF, Deng H, Tang BS, Tang DS, He YG, et al. Identification of a locus for disseminated superficial actinic porokeratosis at chromosome 12q 23.2-24.1. J Invest Dermatol. 2000;114:1071-4.

4. Skupsky H, Skupsky J, Goldenberg G. Disseminated superficial actinic porokeratosis: a treatment review. J Dermatolog Treat. 2012;23:52-6.

5. Gu CY, Zhang CF, Chan LJ, Xiang LH, Zheng ZZ. Clinical analysis and etiology of porokeratosis. Exp Ther Med. 2014;8:737-41.

Copyright by Mrinal Gupta. This is an open access article distributed under the terms of the Creative Commons Attribution License, which permits unrestricted use, distribution, and reproduction in any medium, provided the original author and source are credited Source of Support: Nil, Conflict of Interest: None declared. 